\title{
Prevalence of Antibiotic-resistant Salmonella in Vegetables and Fermented Foods and their Control by Lactic Acid Bacteria
}

\author{
Nawarat Rattanadilok na Phuket ${ }^{1}$ (D), Surasak Siripornadulsil ${ }^{1,3}$ (D) and \\ Wilailak Siripornadulsil ${ }^{1,2,3, *}$ iD
}

${ }^{1}$ Department of Microbiology, Faculty of Science, Khon Kaen University, Khon Kaen, Thailand. ${ }^{2}$ The Center for Alternative Energy Research and Development, Khon Kaen University, Khon Kaen, Thailand. ${ }^{3}$ Research Center for Environmental and Hazardous Substance Management, Khon Kaen University, Khon Kaen, Thailand.

\begin{abstract}
Salmonella is the leading cause of foodborne disease and a public health concern. In this study, food samples were collected from fresh markets within northeastern Thailand. Antibiotic-resistant Salmonella were detected in fresh vegetables and fermented meat products. Of 172 collected food samples, 25 (14.53\%) were contaminated with Salmonella resistant to at least 1 of 9 antibiotics. Eight strains of 7 serovars, including S. Derby, S. Paratyphi B, S. Stanley, S. Dabou, S. Rissen, S. Hvittingfoss, and S. Brenderup, were resistant to $S, T E, C N$, SXT, and NA, accounting for $20 \%, 16 \%, 12 \%, 12 \%$, and $12 \%$ of all antibiotics, respectively. To determine the anti-Salmonella activity of lactic acid bacteria, Pediococcus pentosaceus PS34 isolated from fermented fish was selected from 5 strains of food-derived lactic acid bacteria according to the antibacterial and acid-resistance properties. When added to $3 \mathrm{log} \mathrm{CFU} / \mathrm{ml}$ cultures of Salmonella, the PS34 cell-free supernatant (CFS) reduced the numbers of Salmonella after $1,15,30$, and 60 minutes of incubation; the reduction reached $99.9 \%$ within 30 minutes. The minimal arbitrary inhibition concentration of freeze-dried PS34 CFS was a 1:4 dilution. With the exception of neutralization to $\mathrm{pH} 6.5$, treatment with proteolytic enzymes and heating at $100^{\circ} \mathrm{C}$ and $120^{\circ} \mathrm{C}$ did not reduce the freeze-dried PS34 CFS anti-Salmonella activity, indicating that the extracellular PS34 bioactive substances were heat stable and highly effective against Salmonella in vitro. Thus, bioactive substances produced by P. pentosaceus PS34 have the potential to reduce the risk of antibiotic-resistant Salmonella from contaminated food reaching consumers.
\end{abstract}

Keywords: Antibiotic-resistant Salmonella, Pediococcus pentosaceus, bioactive substance, fresh vegetable, fermented food.

\footnotetext{
*Correspondence: swilai@kku.ac.th
}

(Received: 02 September 2019; accepted: 30 October 2019)

Citation: Nawarat Rattanadilok na Phuket, Surasak Siripornadulsil and Wilailak Siripornadulsil, Prevalence of Antibiotic-resistant Salmonella in Vegetables and Fermented Foods and their Control by Lactic Acid Bacteria, J Pure Appl Microbiol., 2019; 13(4): 1929-1939. https://doi.org/10.22207/JPAM.13.4.05

(C) The Author(s) 2019. Open Access. This article is distributed under the terms of the Creative Commons Attribution 4.0 International License which permits unrestricted use, sharing, distribution, and reproduction in any medium, provided you give appropriate credit to the original author(s) and the source, provide a link to the Creative Commons license, and indicate if changes were made. 


\section{INTRODUCTION}

Salmonella is a leading cause of foodborne disease and a public health concern worldwide. In humans and animals, Salmonella infection causes high morbidity and mortality rates as well as large economic losses ${ }^{1}$. The source of infection is mainly cross-contamination from animal faces and affects a variety of foods, such as poultry, pork, beef, fish, seafood, eggs, milk, cheese, fresh products, and fruit ${ }^{2-4}$. Salmonella is becoming increasingly resistant to various antibiotics via resistance genes against $3^{\text {rd }}$ - and $4^{\text {th }}$-generation beta-lactams ${ }^{5}$, which is becoming a serious problem in Thailand and many countries ${ }^{6}$. The inappropriate uses of antibiotics in animal production is the main reason for antimicrobial resistance in Salmonella, increasing the virulence and invasiveness of strains, making the treatment of the associated infections increasingly difficult and leading to prolonged illnesses ${ }^{7,8}$. In Thailand, Salmonella is present in food products at high levels due to improper hygiene practices during handling and food processing ${ }^{9}$. However, there is still limited information on the incidence of antibiotic-resistant Salmonella in food products ${ }^{10}$.

In recent years, people have begun to demand natural foods without chemical preservatives ${ }^{11}$ due to health concerns regarding chemical food additives ${ }^{12}$. There is increasing interest in the use of natural antimicrobials for food protection and safety that can control both spoilage and pathogenic microorganisms ${ }^{12,13}$. Thus, the use of natural antimicrobials derived from probiotics has become appealing ${ }^{14}$. Many probiotics are lactic acid bacteria (LAB) mainly comprised of Bifidobacterium and Lactobacillus ${ }^{15}$. Other species, such as Pediococcus acidilactici and Pediococcus pentosaceus ${ }^{16}$, also have probiotic properties. In addition to organic acids, probiotics produce a variety of antimicrobial compounds, such as hydrogen peroxide, carbon dioxide, diacetyl, acetaldehyde, D-isomer amino acids, biosurfactants, bacteriocin, and reuterin ${ }^{13}$.

In a previous study, several LAB strains were isolated from various traditional Thai fermented foods and Mekong freshwater fish. Among these, P. pentosaceus PS34 showed the greatest potential probiotic properties, producing many antimicrobial peptides, proteolytic and lipolytic enzymes and several health-benefit- associated substances. These strains also inhibited the growth of the standard $S$. Typhimurium DMST 562 (ATCC13311) strain ${ }^{17}$. Thus, the analysis of the ability of potential LAB strains to inhibit the spread of antibiotic-resistant Salmonella serovars without causing toxicity to food and the environment has gained our attention. The aims of this study were to determine the prevalence of antibiotic-resistant Salmonella in fermented foods and vegetables and to evaluate the antimicrobial activity of the selected probiotic, P. pentosaceus PS34, against antibiotic-resistant Salmonella isolated from food.

\section{MATERIALS AND METHODS \\ Bacterial strains}

Salmonella Typhimurium DMST562 is a standard strain. The antibiotic-resistant Salmonella isolates used in this study originated from fermented foods and vegetables. Five $L A B$ strains of Pediococcus pentosaceus PS34, NP6, BD33, CF32 and SW5, were isolated from fermented fish, fermented pork, Mae Kong river fish ${ }^{18}$.

\section{Collection of food samples}

A total of 172 food samples, including 100 vegetables and 72 Thai fermented foods (pla-som and nham), were purchased from fresh markets in Khon Kaen, Kalasin, Roiet and Mahasarakham provinces, Northeastern Thailand. After collection, the samples were tightly sealed and kept in plastic bags and chilled at $5-8^{\circ} \mathrm{C}$ in a delivery cooler box and analyzed in the laboratory within $24 \mathrm{~h}$.

\section{Isolation and identification of Salmonella}

The isolation and identification of Salmonella was performed according to ISO 6579:2002. Briefly, $25 \mathrm{~g}$ of each food sample was added to $225 \mathrm{ml}$ of buffered peptone water (BPW; Oxoid, Basingstoke, Hampshire, UK) and mixed using a stomacher for 2 minutes. The samples were pre-enriched at $37^{\circ} \mathrm{C}$ for $18 \pm 2 \mathrm{~h}$. The cultures obtained from the pre-enrichment were subcultured in two selective enrichment broths: Rappaport-Vassiliadis medium with soy and a Müllere-Kauffmann tetrathionate broth (Oxoid), and incubated for $24 \pm 3 \mathrm{~h}$ at $41.5 \pm 0.5^{\circ} \mathrm{C}$ and $37 \pm 1^{\circ} \mathrm{C}$, respectively. The enriched cultures were streaked on the XLD and Hextoen (Oxoid) selective plating media and incubated at $37^{\circ} \mathrm{C}$ for $24 \mathrm{~h}$. Salmonella colonies were confirmed by biochemical tests using triple iron agar (TSI), motile indole lysine agar (MIL), urea agar and indole 
tests. The presence of the invasion-associated gene iagA in presumptive colonies displaying typical Salmonella biochemical properties was confirmed by an iQ-Check Salmonella II realtime PCR detection kit (Bio-Rad) according to the manufacturer's instructions. All Salmonella isolates were stored at $-80^{\circ} \mathrm{C}$ in $20 \%$ glycerol until further examination. Presumptive Salmonella colonies were further confirmed by serological tests. The serological somatic $\mathrm{O}$ and $\mathrm{H}$ antigen tests for Salmonella were determined by the Kauffmann-White method ${ }^{19}$ using commercial antisera (S\&A, Thailand).

Screening of antibiotic-resistant Salmonella by disc diffusion

The antibiotic susceptibility was determined on Muller-Hinton agar using the standard disc diffusion method, according to the guidelines of the Clinical and Laboratory Standards Institute (CLSI; Clinical and Laboratory Standards Institute, 2012). A total of 172 Salmonella isolates were screened with nine antibiotic discs (Oxoid, UK), including gentamycin $10 \mu \mathrm{g}(\mathrm{CN})$, tetracycline $30 \mu \mathrm{g}(\mathrm{TE})$, ciprofloxacin $5 \mu \mathrm{g}(\mathrm{CIP})$, sulfamethoxazole-trimethoprim $25 \mu \mathrm{g}$ (SXT), nalidixic acid $30 \mu \mathrm{g}$ (NA), sulfonamides $300 \mu \mathrm{g}$ (S), cephalothin $30 \mu \mathrm{g}(\mathrm{KF})$, neomycin $30 \mu \mathrm{g}$ $(\mathrm{N})$, and nitrofurantoin $300 \mu \mathrm{g}(\mathrm{F})$. The plates were incubated overnight at $37^{\circ} \mathrm{C}$ and $30^{\circ} \mathrm{C}$. The diameters of the inhibition zones were measured and compared with CLSI standards (CLSI, 2017). Quality control tests were performed using $E$. coli ATCC 25922 and S. aureus ATCC 259223 as standard strains. The experiment was carried out in duplicate.

In vitro antimicrobial activity of $P$. pentosaceus BD33, CF32, NP6, PS34 and SW5 LAB crude cellfree supernatant (CFS) against antibiotic-resistant Salmonella

\section{Preparation of crude CFS}

One loop full of fresh culture of each of the 5 LAB strains was cultured in $10 \mathrm{ml}$ of MRS agar at $35^{\circ} \mathrm{C}$ for $24 \mathrm{~h}$ and subcultured with $1 \%$ of LAB culture in $100 \mathrm{ml}$ of MRS at $35^{\circ} \mathrm{C}$ for $24 \mathrm{~h}$. After incubation, the CFS filtrate was obtained by centrifugation at $12,000 \times \mathrm{g}$ for 15 minutes. The supernatant $\mathrm{pH}$ was measured, and the supernatant was sterilized by filtration through a $0.2 \mu \mathrm{m}$ pore size filter. The antimicrobial activity of the untreated CFS ( $\mathrm{pH} \mathrm{4.0)}$ and CFS (pH 6.5) neutralized with $1 \mathrm{~N} \mathrm{NaOH}$ was tested.

Antimicrobial activity determination by agar well diffusion

The antimicrobial activity of CFS derived from P. pentosaceus BD33, CF32, NP6, PS34 and SW5 was tested against 8 Salmonella isolates representing 7 antibiotic-resistant serovars, including S. Paratyphi B, S. Hvittingfoss, S. Stanley,

Table 1. Distribution of Salmonella serovars in vegetables and fermented pork and fish

\begin{tabular}{|c|c|c|c|c|c|}
\hline $\begin{array}{l}\text { Serogroup } \\
\text { (Total) }\end{array}$ & Serovar & Vegetable & $\begin{array}{l}\text { Fermented } \\
\text { pork }\end{array}$ & $\begin{array}{l}\text { Fermented } \\
\text { fish }\end{array}$ & $\begin{array}{c}\text { Total } \\
\text { serotypes }\end{array}$ \\
\hline \multirow[t]{3}{*}{$B(n=3)$} & S. Derby & 1 & 0 & 0 & 1 \\
\hline & S. Paratyphi B & 1 & 0 & 0 & 1 \\
\hline & S. Stanley & 0 & 2 & 1 & 3 \\
\hline \multirow[t]{8}{*}{$C(n=8)$} & S. Brenderup & 0 & 1 & 0 & 1 \\
\hline & S. Brunei & 3 & 0 & 1 & 4 \\
\hline & S. Choleraesuis & 1 & 0 & 0 & 1 \\
\hline & S. Dabou & 1 & 0 & 0 & 1 \\
\hline & S. Newport & 1 & 0 & 0 & 1 \\
\hline & S. Rissen & 1 & 1 & 0 & 2 \\
\hline & S. Tennessee & 0 & 0 & 2 & 2 \\
\hline & S. Virchow & 1 & 0 & 0 & 1 \\
\hline$E(n=1)$ & S. Weltevreden & 1 & 0 & 1 & 2 \\
\hline I $(n=1)$ & S. Hvittingfoss & 3 & 0 & 0 & 3 \\
\hline$X(n=1)$ & S. Bergen & 1 & 0 & 0 & 1 \\
\hline$Y(n=1)$ & S. Djakarta & 1 & 0 & 0 & 1 \\
\hline $\begin{array}{l}\text { Total positive } \\
\text { samples }\end{array}$ & & 16 & 4 & 5 & 25 \\
\hline Percentage & & 64 & 16 & 20 & 100 \\
\hline
\end{tabular}


S. Brenderup, S. Rissen, $S$. Dabou, and S. Derby. A $24 \mathrm{~h}$ culture grown in LB at $37^{\circ} \mathrm{C}$ was adjusted to 0.5 McFarland standards, swabbed on LB agar plates with a sterile cotton swab, allowed to dry, and a hole was punched in the agar with a sterile $6 \mathrm{~mm}$ cork-borer. Each well was filled with $60 \mu \mathrm{l}$ of CFS obtained from the $P$. pentosaceus isolates. After incubation at $37^{\circ} \mathrm{C}$ for 24,36 and $48 \mathrm{~h}$, the inhibition zones around the well were measured. A $0.8 \%$ lactic acid solution and MRS broth were used as positive and negative controls, respectively. The results were considered positive if the diameter of the inhibition zone was greater than $10 \mathrm{~mm}$. The experiment was carried out in triplicate.

Antimicrobial activity determination by broth method

Eight strains of antibiotic-resistant Salmonella were grown in LB broth at $37^{\circ} \mathrm{C}$ for $24 \mathrm{~h}$. Serial dilutions were performed in LB broth to obtain approximate cell concentrations at 3 Log CFU/ml, and $5 \mathrm{ml}$ of CFS was added. After incubation for $1,15,30$, and 60 minutes, samples

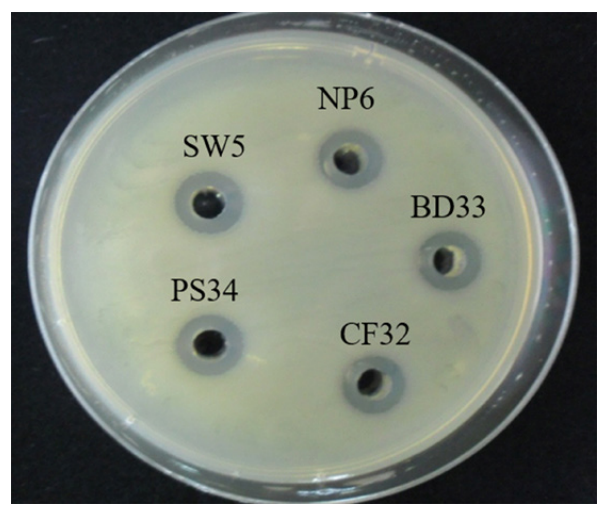

Fig. 1. Inhibitory effect of untreated CFS from overnight cultures of 5 strains of $P$. pentosaceus in MRS broth at pH 4.0 on S. Typhimurium DMST562

Table 2. Antibiotic resistance profiles of Salmonella isolated from vegetables and fermented meats

\begin{tabular}{lccc}
\hline Salmonella & Food type & Food origin & $\begin{array}{c}\text { Antibiotic- } \\
\text { resistance profiles }\end{array}$ \\
\hline S. Paratyphi B & Vegetable & Lettuce & CN \\
S. Dabou & Vegetable & Parsley & NA \\
S. Hvittingfoss & Vegetable & Water cress & NA, CN \\
S. Rissen & Vegetable & Lettuce & TE, S, SXT \\
S. Derby & Vegetable & Coriander & NA, TE, S, SXT \\
S. Brenderup & Fermented pork & Nham & S \\
S. Stanley (P) & Fermented pork & Nham & TE, CN \\
S. Stanley (F) & Fermented fish & Pla-som & TE, S, SXT \\
Journal of Pure and Applied Microbiology & \multicolumn{2}{c}{1932} &
\end{tabular}

were taken, and Salmonella survival was assessed by plating the samples on LB agar plates and counting the colonies after incubation at $37^{\circ} \mathrm{C}$ for $24 \mathrm{~h}$. S. Typhimurium DMST562 and sterilized distilled water were used as positive and negative controls, respectively. The number of surviving Salmonella was calculated as follows:

$\%$ Reduction $=\left(1-10^{-L}\right) \times 100, L=$ Log reduction $\%$ Survival $=100-\left(1-10^{-L}\right) \times 100$

\section{In vitro antimicrobial activity of lyophilized and concentrated PS34 CFS against antibiotic-resistant Salmonella}

One loop full of fresh culture of the 8 $\mathrm{LAB}$ strains was cultured in $10 \mathrm{ml}$ of MRS at $35^{\circ} \mathrm{C}$ for $24 \mathrm{~h}$ and subcultured with $1 \%(\mathrm{v} / \mathrm{v})$ of $L A B$ culture in $100 \mathrm{ml} \mathrm{MRS}$ at $35^{\circ} \mathrm{C}$ for $24 \mathrm{~h}$. The crude P34 CFS was concentrated and preserved by the freeze-drying method. The freeze-dried CFS was resuspended in $5 \mathrm{ml}$ of sterile distilled water and filtered through a $0.2 \mu \mathrm{m}$ cellulose acetate filter. The optimal inhibitory activity of the CFS against Salmonella was assessed. The CFS was serially diluted to $1: 1,1: 2,1: 4,1: 8,1: 16,1: 32$ and $1: 64$ ratios in MRS broth, and $10 \mu$ l of each was dropped on an LB agar. The inhibition zone was measured. The experiment was carried out in triplicate.

Effects of proteolytic enzymes, $\mathrm{pH}$ and temperature on the antimicrobial activity of the CFS

The lyophilized CFS was treated with different conditions as follows: heat by boiling at $100^{\circ} \mathrm{C}$ for 30 minutes and autoclaving at $121^{\circ} \mathrm{C}$ for 15 minutes; treated with trypsin, pepsin, proteinase $\mathrm{K}$ at a final concentration of $1 \mathrm{mg} / \mathrm{ml}$, and the $\mathrm{pH}$ was adjusted to 6.5 using $1 \mathrm{M} \mathrm{NaOH}$. MRS broth was used as the negative control. Then, the antimicrobial activity of the treated CFS was 
tested against Salmonella by drop diffusion as described above.

\section{RESULTS}

Prevalence and serotyping of antibiotic-resistant Salmonella isolated from vegetables and fermented foods

Salmonella were detected in 25 of all 172 samples (14.53\%). The isolates were derived from 16 of 100 vegetables (16\%) and 9 of 72 fermented meat samples (12.5\%). All Salmonella isolates expressed the invasion-associated gene $\operatorname{iagA}$, as assessed by an iQ-Check Salmonella II real-time PCR detection kit. In this study, 25 Salmonella isolates were classified into 6 serogroups and 15 serovars. The type and numbers of the serogroups were as follows: $\mathrm{B}-3, \mathrm{C}-8, \mathrm{E}-1, \mathrm{I}-1, \mathrm{X}-1$ and $\mathrm{Y}-1$, in which serogroup $C(32 \%)$ was the most abundant. Antibiotic-resistant Salmonella were detected in $64 \%, 20 \%$, and $16 \%$ of vegetable, fermented fish, and fermented pork samples, respectively (Table 1).

\section{Antimicrobial susceptibility of antibiotic-resistant} Salmonella isolates

In total, the antimicrobial susceptibility of 25 isolates covering 15 serovars was tested against 9 antimicrobial agents. Resistant Salmonella isolates were categorized into 8 serovars ( $S$. Brenderup S. Dabou, S. Derby, S. Hvittingfoss, S. Paratyphi B, S. Rissen, S. Stanley and S. Tennessee).

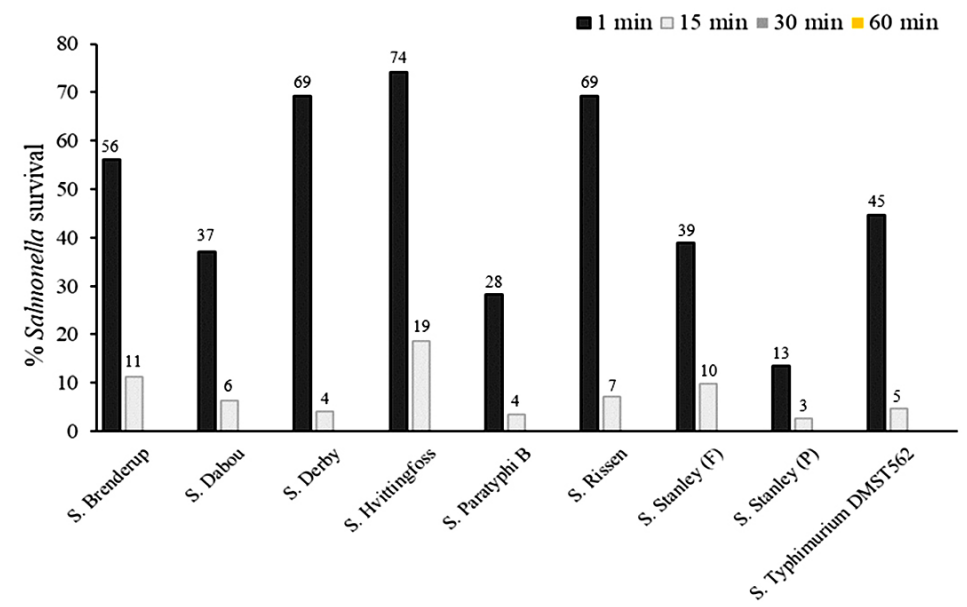

Fig. 2. Survival of antibiotic-resistant Salmonella serovars after contact with crude $P$. pentosaceus PS34 CFS for 1 , 15, 30 and 60 minutes.

Table 3. Antibiotic-resistance percentages of Salmonella isolated from vegetables and fermented meats

\begin{tabular}{lcccc}
\hline Antibiotics $(\mu \mathrm{g})$ & \multicolumn{4}{c}{$\begin{array}{c}\text { No. of Salmonella isolates (\%) } \\
(\mathrm{n}=25)\end{array}$} \\
\cline { 3 - 5 } & & $\mathrm{S}$ & $\mathrm{I}$ & $\mathrm{R}$ \\
\hline Cephalothin (30) & $\mathrm{KF}$ & $25(100)$ & $0(0)$ & $0(0)$ \\
Ciprofloxacin (5) & $\mathrm{CIP}$ & $25(100)$ & $0(0)$ & $0(0)$ \\
Gentamycin (10) & $\mathrm{CN}$ & $22(88)$ & $0(0)$ & $3(12)$ \\
Nalidixic acid (30) & $\mathrm{NA}$ & $20(80)$ & $2(0)$ & $3(12)$ \\
Neomycin (30) & $\mathrm{N}$ & $0(0)$ & $25(100)$ & $0(0)$ \\
Nitrofurantoin (300) & $\mathrm{F}$ & $25(100)$ & $0(0)$ & $0(0)$ \\
Sulfonamides (300) & $\mathrm{S}$ & $17(68)$ & $3(12)$ & $5(20)$ \\
Sulfamethoxazole- & & & & \\
Trimethoprim (25) & SXT & $22(88)$ & $0(0)$ & $3(12)$ \\
Tetracycline (30) & TE & $20(80)$ & $1(4)$ & $4(16)$ \\
\hline
\end{tabular}

S: Susceptible; I: Intermediate; R: Resistant 
These resistant Salmonella isolates were resistant to at least one antibiotic. The percentages of strains resistant to sulfonamides $(300 \mu \mathrm{g})$, tetracycline (30 $\mu \mathrm{g})$, gentamicin $(30 \mu \mathrm{g})$, nalidixic acid $(30 \mu \mathrm{g})$, and sulfamethoxazole (25 $\mu \mathrm{g}$ ) were $20 \%, 16 \%, 12 \%$, $12 \%$, and $12 \%$, respectively. None of the isolates were found to be resistant to ciprofloxacin (50 $\mu \mathrm{g})$, cephalothin $(30 \mu \mathrm{g})$, neomycin $(30 \mu \mathrm{g})$ or nitrofurantoin $(300 \mu \mathrm{g})$, as shown in Tables 2 \& 3 . Antimicrobial activity of LAB strains against antibiotic-resistant Salmonella

Due to their potential probiotic properties, including susceptibility to many antibiotics, inhibition of Gram positive and negative bacterial pathogens, and tolerance to low $\mathrm{pH}$ in the presence of inulin (a prebiotic) ${ }^{17,18}$, the antimicrobial activity of crude $P$. pentosaceus BD33, CF32, NP6, PS34 and SW5 CFS was investigated. The CFS of all $P$. pentosaceus strains was prepared as untreated $(\mathrm{pH} 4)$ and neutralized $(\mathrm{pH} \mathrm{6.5)}$ and tested against Salmonella using the agar well diffusion

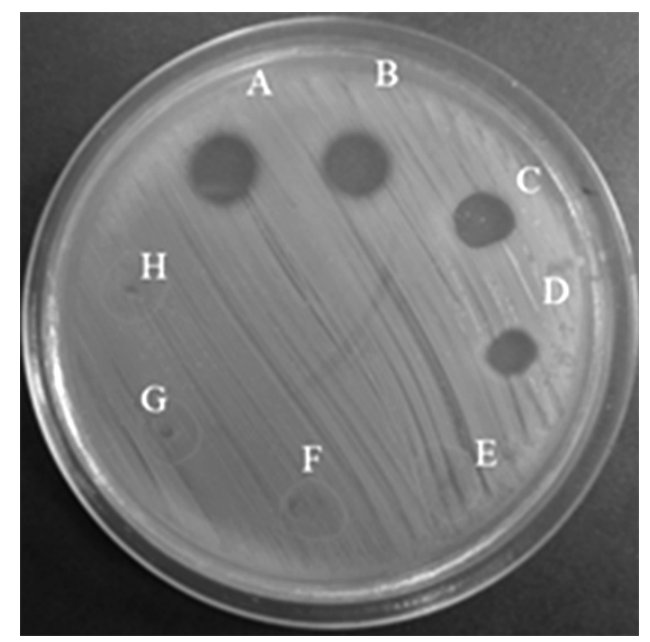

Fig. 3. Minimal arbitrary inhibition concentration of freeze-dried PS34 CFS against S. Typhimurium DMST562 (A undiluted, B 1:1, C 1:2, D 1:4, E 1:8, F 1:16, G 1:32, and $\mathrm{H}$ 1:64). method. The untreated CFS of all strains showed an inhibition zone of approximately $12.3 \mathrm{~mm}$ against $S$. Typhimurium after $24 \mathrm{~h}$ of incubation (Fig. 1). However, no inhibition zone was detected for neutralized CFS ( $\mathrm{pH}$ 6.5). PS34 exhibited the greatest tolerance in the presence of inulin to $\mathrm{pH}$ 2 after $24 \mathrm{~h}^{18}$, therefore PS34 CFS samples were tested against 8 isolates of antibiotic-resistant Salmonella and S. Typhimurium DMST562. The results showed that after prolonged incubation for 36 and $48 \mathrm{~h}$, the inhibition zone increased slightly (Table 4). The $0.8 \%$ lactic acid control showed an inhibition zone of $11.6 \mathrm{~mm}$, and the zone size was not altered after prolonged incubation. Generally, $L A B$ produce the greatest amount of lactic acid at $24 \mathrm{~h}$ incubation. Thus, the increase in the inhibition zone after $24 \mathrm{~h}$ was derived possibly from other factors, such as bioactive substances.

Antimicrobial activity of crude PS34 CFS when mixed with Salmonella cultures for $1,15,30$, and 60 minutes

PS34 CFS reduced the number of Salmonella cells during the first one minute incubation by as much as $87 \%$ (survived $13 \%$ ) for S. Stanley (P) (Fig. 2). The numbers of all tested Salmonella serovars decreased significantly with the survival at only 3-11\% after 15 minutes. Incubation with the CFS reduced the numbers of Salmonella by approximately $99.9 \%$ within 30 minutes. Finally, the PS34 CFS eliminated all tested Salmonella at 60 minutes, in which the cell numbers were reduced by $99.98 \%$. After $24 \mathrm{~h}$, Salmonella cell survival was not detected, suggesting that Salmonella were completely eliminated.

Determination of the antimicrobial activity of freeze-dried $P$. pentosaceus PS34 CFS by drop diffusion

The 2-fold diluted solution of freezedried PS34 CFS was mixed with the cultures of the 8 antibiotic-resistant Salmonella isolates, and

Table 4. The growth inhibition of antibiotic-resistant Salmonella and S. Typhimurium DMST562 by crude PS34 CFS ( $\mathrm{pH} 4)$ with $0.8 \%$ lactic acid and MRS broth used as positive and negative controls.

\begin{tabular}{llllll}
\hline Strains & \multicolumn{5}{c}{ Inhibition zone $(\mathrm{mm})$} \\
\cline { 2 - 5 } & $24 \mathrm{~h}$ & $36 \mathrm{~h}$ & $48 \mathrm{~h}$ & $\begin{array}{c}0.8 \% \\
\text { lactic acid }\end{array}$ & MRS
\end{tabular}

Antibiotic-resistant Salmonella S. Typhimurium DMST562 12.5 12.7 13.5 11.6 
the inhibition zone was measured. The minimal arbitrary inhibition concentration of all samples was found to be a 1:4 dilution, and the growth inhibition effect was lost beyond a 1:8 dilution (Fig. 3).

Effect of heat, proteolysis, and $\mathrm{pH}$ on the antiSalmonella activity of the freeze-dried PS34 CFS

When tested with all 8 isolates of Salmonella, the anti-Salmonella activity of the PS34 CFS remained but decreased slightly after heating $\left(100^{\circ} \mathrm{C}\right.$ for 30 minutes and $121^{\circ} \mathrm{C}$ for 15 minutes) and digestion with proteolytic enzymes (trypsin, pepsin, and proteinase K; Table 5). Only a pH of 7 negatively affected the inhibitory activity. It has been reported that lactic acid from LAB fermentation broth is sensitive to heat at approximately $111^{\circ} \mathrm{C}^{20}$. Thus, the inhibitory activity of PS34-CFS at $121^{\circ} \mathrm{C}$ was likely derived from antimicrobial agents and/or acid.

Table 5. Diameter of the PS34 CFS-induced S. Typhimurium DMST562 inhibition zones after heat treatment, proteolytic enzyme treatment, or $\mathrm{pH}$ neutralization

\begin{tabular}{lccccc}
\hline Strains & \multicolumn{4}{c}{ Diameter of inhibition zone of treated CFS (mm) } \\
\cline { 2 - 5 } & $\begin{array}{c}121^{\circ} \mathrm{C} \\
15 \text { minutes }\end{array}$ & $\begin{array}{c}100^{\circ} \mathrm{C} \\
30 \text { minutes }\end{array}$ & $\begin{array}{c}\text { Trypsin, Pepsin, } \\
\text { Proteinase K }\end{array}$ & $\mathrm{pH} \mathrm{7}$ & Untreated \\
\hline $\begin{array}{l}\text { S. Typhimurium } \\
\text { DMST562 }\end{array}$ & 11.25 & 10 & 12 & 12.25 & 12 \\
\hline
\end{tabular}

\section{DISCUSSION}

The resistance of Salmonella to many antibiotics has become a serious health problem worldwide ${ }^{14}$. In this study, the prevalence of Salmonella in vegetables and traditional Thai fermented pork (nham-mooh) and fermented fish (pla-som fak) sold in the local fresh markets and supermarkets in the northeastern region was $64 \%$ in vegetables and $36 \%$ in meat/fish. In this study, $S$. Typhimurium and $S$. Enteritidis, major infectious serovars in humans, were not detected. Of the Salmonella isolates, $20 \%, 16 \%, 12 \%, 12 \%$, and $12 \%$, were resistant to sulfonamides, tetracycline, gentamicin, nalidixic, and sulfamethoxazole, respectively. Among the antibiotic-resistant isolates, $12.5 \%$ and $16 \%$ were isolated from fresh vegetables and fermented meats, respectively. In agreement with previous studies, Salmonella from the meat products in retail markets in Thailand were resistant to ampicillin, sulfonamides and tetracycline ${ }^{21}$.

These results are similar to those in a report from Tunisia $(20 \%)^{22}$ but lower than those detected previously in Morocco $(75.43 \%)^{23}$, Italy $(84.2 \%)^{24}$ and China $(74 \%)^{25}$. In this study, $14.7 \%$ of Salmonella isolates (5/34) were resistant to two types of antibiotics. These rates are lower than those found in Botswana $(20.3 \%)^{26}$ and Egypt $(100 \%)^{27}$. The percentage of isolates resistant to tetracycline was $16.0 \%$. Resistance to these antimicrobials is common in Salmonella isolates and has been observed previously in Morocco $^{23}$, Tunisia $^{22}$, Malaysia ${ }^{28}$ and China ${ }^{29}$. The prevalence of sulfonamide resistance is signi cant (20\%), and might be a consequence of the widespread use of these antimicrobials in livestock. This percentage is consistent with that detected in Morocco $(20.5 \%)^{30}$ but higher than that found in Tunisia $(1.2 \%)^{22}$.

The Salmonella observed in this present study were determined by the detection of invasion-associated (iagA) genes. All positive isolates expressed the $\operatorname{iagA}$ gene, indicating that the consumption of raw nham-mooh, pla-som fak and fresh vegetables might lead to an increased risk of antibiotic-resistant Salmonella infection due to the transfer of resistance genes to other bacteria. However, further epidemiological studies and more data regarding the link between contaminated food consumption, human illness and the presence of virulence genes may be necessary to address food safety concerns.

The presence of several Salmonella serovars in foods points to natural crosscontamination in the environment. The prevalence of the predominant Salmonella serotypes in this study might be different from that in other geographical regions due to several factors, such as the environment and temperature ${ }^{30}$. The cross- 
contamination of the raw material usually occurs at its point of origin, such as the cross-contamination in fish, which usually occurs via exposure of the fish to various pathogens in aquatic environments ${ }^{31}$. The cross-contamination of vegetables usually occurs by fecal contamination of the water used for irrigation and food processing ${ }^{31}$. The low hygienic quality of food processing facilities mainly leads to cross-contamination due to a lack of good handler hygiene practices, such as hand washing during raw material handling, delivery and food processing steps ${ }^{32,33}$. In addition, techniques used for the isolation of pathogenic bacteria might be different ${ }^{30}$.

In Thailand, the small-scale production of many traditional fermented Thai meats such as nham-moo and pla-som-fak are processed by indigenous microorganisms, which could be contaminated with pathogens. Traditional Thai fermented food products are commonly produced at home or by small-scale industrial production and sold at small retail markets in upper northeastern Thailand. Hence, contamination with widespread foodborne pathogens, such Salmonella, could easily occur, and approaches to prevent this occurrence should be investigated.

In this study, we sought to determine the potential of natural antimicrobials to control pathogenic microorganism growth for food protection and safety as an alternative choice to current food preservatives ${ }^{12,13}$. The CFS from potential probiotic bacteria $P$. pentosaceus PS34 showed strong inhibitory activity against antibiotic-resistant Salmonella strains isolated from fresh vegetables and fermented foods. Our results are consistent with those of a previous study reporting that probiotic $L A B$ inhibit the growth of various Gram-positive and Gramnegative pathogenic bacteria. The use of CFS from L. rhamnosus and L. casei combined with amikacin and gentamicin strongly inhibited the development of a Pseudomonas aeruginosa infection ${ }^{34}$. Qureshi et al. (2019) ${ }^{35}$ reported that the use of probiotics combined with a conventional antibiotic regimen appeared has great potential for eliminating Helicobacter pylori infections. However, the use of probiotics with antibiotic-resistant microorganisms could have both beneficial effects and risks. Therefore, the regulation of the use of probiotics in both humans and animals should be appropriately established $^{8}$.

P. pentosaceus PS34 was isolated from fermented fish and is a potential probiotic strain due to its susceptibility to many antibiotics ${ }^{18}$. The CFS from $P$. pentosaceus PS34 may have inhibited the growth of Salmonella through the production of various antimicrobial compounds. LAB normally produce weak organic acids in the medium. Weak organic acids, such as lactic acid, can penetrate through the cell membranes of Gram-negative bacteria, causing intracellular acidification after the release of hydrogen ions $\mathrm{s}^{36}$. This acidification leads to the loss of ATP from the cell. The intracellular hydrogen ions diffuse passively out of the bacterial cells across the membrane, resulting in cell damage and cell death $^{37}$. Bacteriocin is a ribosomally synthesized antimicrobial peptide commonly produced by LAB. Bacteriocin works mainly against Gram-positive bacteria ${ }^{38}$. Many bacteriocins are heat stable, and the widely studied bacteriocin from LAB has gained increased attention as an alternative means to inhibit pathogens growth in foods ${ }^{39}$. In this study, the antimicrobial effect of CFS against Salmonella might also involve bacteriocin activity since the inhibition remained after the CFS was heated at high temperatures. Out of the total samples, Salmonella were isolated from $36 \%$ of fermented meats, which normally have a low $\mathrm{pH}$, indicating that Salmonella are naturally able to tolerate acid. The inhibitory effect observed in this study was possibly derived from bioactive substances. However, the loss of CFS activity at neutral $\mathrm{pH}$ indicates that the PS34-derived bioactive substance favors $\mathrm{pH} 4$.

The high prevalence of antibioticresistant Salmonella (at 64\%) in fresh vegetables observed in this study is a public safety concern. To minimize the risk of human infection, it is important to continue surveillance and take measures to prevent food and environmental contamination by antimicrobial-resistant bacteria as well as to educate the public that avoiding raw food consumption is important to prevent antimicrobial-resistant bacterial infections. Thus, public health authorities should monitor and provide information and knowledge to customers for safe food consumption. New decontamination 
methods are needed to guarantee the safety of various foods ${ }^{40-43}$. Therefore, the regulation of the use of probiotics in both humans and animals should be appropriately established ${ }^{8}$.

\section{CONCLUSION}

In conclusion, the contamination of vegetables and fermented meats with antibioticresistant Salmonella is widespread, indicating the inappropriate use of antimicrobial antibiotics in humans and livestock. Salmonella crosscontaminate the environment, and thus the transference of antibiotic-resistance genes to other bacteria is possible. This study revealed the antimicrobial properties of CFS from $P$. pentosaceus PS34 originally derived from fermented fish, which was effective against a variety of antibioticresistant Salmonella serovars isolated from foods. Thus, PS34 has the potential to inhibit the growth of antimicrobial-resistant Salmonella, indicating that it may be useful in food or in the environment to improve the quality of food products by inhibiting the growth of contaminating antibioticresistant Salmonella.

\section{ACKNOWLEDGEMENTS}

We would like to express our grateful thanks to Ms. Siriyanapat Tasaku for her assistance with the LAB experiments.

\section{CONFLICTS OF INTEREST}

The authors declare that there is no conflict of interest.

\section{AUTHOR CONTRIBUTION}

WS and NR designed the experiments. NR performed the experiments. WS and NR analyzed the data and wrote the manuscript. WS, NR and SS read and approved the manuscript.

\section{FUNDING}

None.

\section{DATA AVAILABILITY}

All datasets generated or analyzed during this study are included in the manuscript.

\section{ETHICS STATEMENT}

Not applicable.

\section{REFERENCES}

1. Scallan, E, Hoekstra RM, Angulo FJ, Tauxe RV, Widdowson MA, Roy SL, Jones RL, Griffin PM. Foodborne illness acquired in the United States-major pathogens. Emerging infectious diseases, 2011; 17(1): 7-15. https://doi.org/10.3201/eid1701.P11101

2. Bangtrakulnonth A, Pornreongwong S, Pulsrikarn C, Sawanpanyalert P, Hendriksen R S, Lo Fo Wong DMA, Aarestrup FM. Salmonella serovars from humans and other sources in Thailand, 1993-2002. Emerging infectious diseases, 2004; 10(1): 131-136. https://doi. org/10.3201/eid1001.02-0781

3. Gorski L, Parker CT, Liang A, Cooley MB, Jay-Russell MT, Gordus AG, Mandrell R E. Prevalence, distribution, and diversity of Salmonella enterica in a major produce region of California. Appl. Environ. Microbiol., 2011; 77(8): 2734-2748. https://doi.org/10.1128/ AEM.02321-10

4. Andino A, Hanning I. Salmonella enterica: survival, colonization, and virulence differences among serovars. The Sci. World J., 2015; 520179. https://doi. org/10.1155/2015/520179

5. Maka L, Popowska M. Antimicrobial resistance of Salmonella isolated from food. Roczniki Panstwowego Zakladu Higieny, 2016; 67(4): 343-358.

6. Utrarachkij F, Nakajima C, Siripanichgon K, Changkaew K, Thongpanich Y, Pornraungwong S, Suzuki Y. Genetic diversity and antimicrobial resistance pattern of Salmonella enterica serovar Enteritidis clinical isolates in Thailand. J. Infection Chemotherapy, 2016; 22(4): 209-215. https://doi.org/10.1016/j.jiac.2015.12.011

7. Murgia $M$, Bouchrif B, Timinouni $M$, Al-Qahtani A, Al-Ahdal MN, Cappuccinelli P, Paglietti B. Antibiotic resistance determinants and genetic analysis of Salmonella enterica isolated from food in Morocco. Int. J. Food Microbiol., 2015; 215: 31-39. https://doi. org/10.1016/j.ijfoodmicro.2015.08.003

8. Imperial IC, Ibana JA. Addressing the antibiotic resistance problem with probiotics: reducing the risk of its double-edged sword effect. Frontiers in Microbiology, 2016; 7: 1983. https://doi.org/10.3389/ fmicb.2016.01983

9. Trongjit S, Angkititrakul S, Tuttle RE, Poungseree J, Padungtod P, Chuanchuen R. Prevalence and antimicrobial resistance in Salmonella enterica isolated from broiler chickens, pigs and meat products in Thailand-Cambodia border provinces. Microbiology and Immunology, 2017; 61(1): 23-33. https://doi. org/10.1111/1348-0421.12462

10. Whistler T, Sapchookul P, McCormick DW, Sangwichian O, Jorakate P, Makprasert S, Supcharassaeng S. Epidemiology and antimicrobial resistance of invasive non-typhoidal Salmonellosis in rural Thailand from 2006-2014. PLoS Neglected Trop. Diseases, 2018; 12(8): e0006718. https://doi.org/10.1371/journal. pntd.0006718

11. da Silva Sabo S, Vitolo M, Gonzalez JMD, de Souza Oliveira RP. Overview of Lactobacillus plantarum as a promising bacteriocin producer among lactic acid bacteria. Food Research Int., 2014; 64: 527-536. https://doi.org/10.1016/j.foodres.2014.07.041 
12. Saraoui T, Cornet J, Guillouet E, Pilet MF, Chevalier F, Joffraud JJ, Leroi F. Improving simultaneously the quality and safety of cooked and peeled shrimp using a cocktail of bioprotective lactic acid bacteria. Int. J. Food Microbiol, 2017; 241: 69-77. https://doi.org/10.1016/j. ijfoodmicro.2016.09.024

13. Hartmann HA, Wilke T, Erdmann R. Efficacy of bacteriocin-containing cell-free culture supernatants from lactic acid bacteria to control Listeria monocytogenes in food. Inter. J. Food Microbiol, 2011; 146(2): 192-199. https://doi.org/10.1016/j. ijfoodmicro.2011.02.031

14. Nami Y, Haghshenas B, Abdullah N, Barzegari A, Radiah D, Rosli R, Khosroushahi AY. Probiotics or antibiotics: future challenges in medicine. J. Medical Microbiology, 2015; 64(2): 137-146. https://doi.org/10.1099/ jmm.0.078923-0

15. Nami Y, Haghshenas B, Khosroushahi AY. Molecular identification and probiotic potential characterization of lactic acid bacteria isolated from human vaginal microbiota. Adv. Pharm. Bulletin, 2018; 8(4): 683. https://doi.org/10.15171/apb.2018.077

16. Martinez MP, Gonzalez Pereyra ML, Pena GA, Poloni V, Fernandez Juri G, Cavaglieri LR. Pediococcus acidilactici and Pediococcus pentosaceus isolated from a rainbow trout ecosystem have probiotic and ABF1 adsorbing/degrading abilities in vitro. Food Additives \& Contaminants: Part A, 2017; 34(12), 2118-2130. https://doi.org/10.1080/19440049.2017.1371854

17. Tasaku S, Siripornadulsil S, Siripornadulsil W. Inhibitory activity of food-originated $P$. pentosaceus NP6 against S. enterica serovar Typhimurium in Nile Tilapia byproducts. Chiang Mai J. Sci, 2017; 44, 383-393.

18. Tasaku, S. Isolation and characterization of lactic acid bacteria for potential use as probiotics in fermented Tilapia belly flap meat. Master of Science Thesis, Khon Kaen University, Khon Kaen, Thailand, 2014.

19. Issenhuth-Jeanjean S, Roggentin P, Mikoleit M, Guibourdenche M, de Pinna E, Nair S, Fields PI, Weill FX. Supplement 2008-2010 (no. 48) to the WhiteKauffmann-Le Minor scheme. Research Microbiol, 2014; 165: 526-530. https://doi.org/10.1016/j. resmic.2014.07.004

20. Chen L, Zeng A, Dong H, Li Q, Niu C, A novel process for recovery and refining of $L$-lactic acid from fermentation broth. Bioresource Technology, 2012;112: 280-284. https://doi.org/10.1016/j.biortech.2012.02.100

21. Wannaprasat W, Padungtod P, Chuanchuen R. (2011). Class 1 integrons and virulence genes in Salmonella enterica isolates from pork and humans. Int. J. Antimicrob. Agents, 2011;37: 457-61. https://doi. org/10.1016/j.ijantimicag.2010.12.001

22. Abbassi-Ghozzi I. Jaouani A, Hammami S, MartinezUrtaza J, Boudabous M, Gtari A. Molecular analysis and antimicrobial resistance of Salmonella isolates recovered from raw meat marketed in the area of "Grand Tunis" Tunisia. Pathol. Biol. 2012; 60: e49-54. https://doi.org/10.1016/j.patbio.2011.07.005

23. Chaiba A, Rhazi Filali F, Chahlaoui A, Soulayman Benchikh S, Zerhouni M. Prevalence and anti-microbial susceptibility of Salmonella isolates from chicken carcasses and giblets in Meknes, Morocco. Afr. J.
Microbiol. Res. 2009; 3(5): 215-219.

24. Proroga YTR, Capuano F, Carullo MR, La Tela I, Capparelli R, Barco L, Pasquale V. Occurrence and antimicrobial resistance of Salmonella strains from food of animal origin in southern Italy. Folia Microbiol, 2015; 61: 21-27. https://doi.org/10.1007/s12223-0150407-x

25. Yang X, Huang J, Wu Q, Zhang J, Liu S, Guo W, Yu $S$. Prevalence, antimicrobial resistance and genetic diversity of Salmonella isolated from retail ready-to-eat foods in China. Food Control, 2016; 60: 50-56. https:// doi.org/10.1016/j.foodcont.2015.07.019

26. Mrema N, Mpuchane S, Gashe BA. Prevalence of Salmonella in raw minced meat, raw fresh sausages and raw burger patties from retail outlets in Gaborone, Botswana, Food Control, 2006; 17(3): 207-212. https:// doi.org/10.1016/j.foodcont.2004.09.019

27. Sallam KI, Mohammed MA, Hassan MA, Tamura T. Prevalence, molecular identi cation and antimicrobial resistance pro le of Salmonella serovars isolated from retail beef products in Mansoura, Egypt. Food Control, 2014; 38: 209-214. https://doi.org/10.1016/j. foodcont.2013.10.027

28. Adzitey F, Rusul G, Huda N. Prevalence and antibiotic resistance of Salmonella serovars in ducks, duck rearing and processing environments in Penang, Malaysia. Food Res. Int. 2012; 45: 947-952. https:// doi.org/10.1016/j.foodres.2011.02.051

29. Li Y, Cai Y, Tao J, Kang X, Jiao Y, Guo R, Wang G, Pan Z, Jiao X. Salmonella isolated from the slaughterhouses and correlation with pork contamination in free market, Food Control, 2016;59: 591-600. https://doi. org/10.1016/j.foodcont.2015.06.040

30. Ed-dra A, Filali FR, Karraouan B, El Allaoui A, Aboulkacem A, Bouchrif B. Prevalence, molecular and antimicrobial resistance of Salmonella isolated from sausages in Meknes, Morocco. Microbial Pathogenesis, 2017; 105: 340-345. https://doi.org/10.1016/j. micpath.2017.02.042

31. Benhamed S, Guardiola FA, Mars M, Esteban M. Pathogen bacteria adhesion to skin mucus of fishes. Vet. Microbiol, 2014; 171(1-2): 1-12. https://doi. org/10.1016/j.vetmic.2014.03.008

32. Guevremont E, Lamoureux L, Genereux M, Cote C. Irrigation water sources and time intervals as variables on the presence of Campylobacter spp. and Listeria monocytogenes on Romaine lettuce grown in muck Soil. J. Food Protection, 2017; 80(7): 1182-1187. https://doi.org/10.4315/0362-028X.JFP-16-551

33. Falardeau J, Johnson RP, Pagotto F, Wang S. Occurrence, characterization, and potential predictors of verotoxigenic Escherichia coli, Listeria monocytogenes, and Salmonella in surface water used for produce irrigation in the Lower Mainland of British Columbia, Canada. PLOS ONE, 2017; 12(9): e0185437. https:// doi.org/10.1371/journal.pone.0185437

34. Aminnezhad S, Kermanshahi RK, Ranjbar R. Evaluation of synergistic interactions between cell-free supernatant of Lactobacillus strains and amikacin and genetamicin against Pseudomonas aeruginosa. Jundishapur J. Microbiology, 2015; 8(4): e16592. https://doi.org/10.5812/jjm.8(4)2015.16592 
35. Qureshi N, Li P, Gu Q. Probiotic therapy in Helicobacter pylori infection: a potential strategy against a serious pathogen? Appl. Microbiol. Biotechnol., 2019; 103(4): 1573-1588. https://doi.org/10.1007/s00253-01809580-3

36. Mariam SH, Zegeye N, Aseffa A, Howe R. Diffusible substances from lactic acid bacterial cultures exert strong inhibitory effects on Listeria monocytogenes and Salmonella enterica serovar Enteritidis in a coculture model. BMC Microbiology, 2017; 17(1): 35. https://doi.org/10.1186/s12866-017-0944-3

37. Kavitake D, Kandasamy S, Devi PB, Shetty PH. Recent developments on encapsulation of lactic acid bacteria as potential starter culture in fermented foods-A review. Food Bioscience, 2018; 21: 34-44. https://doi. org/10.1016/j.fbio.2017.11.003

38. Cotter PD, Hill C, Ross RP. Food microbiology: bacteriocins: developing innate immunity for food. Nature Rev. Microbiology, 2005; 3(10): 777-788. https://doi.org/10.1038/nrmicro1273

39. Iglesias MB, Lopez ML, Echeverroa G, Vinas I, Zudaire L, Abadias M. Evaluation of biocontrol capacity of
Pseudomonas graminis CPA-7 against foodborne pathogens on fresh-cut pear and its effect on fruit volatile compounds. Food Microbiology, 2018; 76: 226-236. https://doi.org/10.1016/j.fm.2018.04.007

40. $\mathrm{Xu} \mathrm{W,} \mathrm{Wu} \mathrm{C.} \mathrm{The} \mathrm{impact} \mathrm{of} \mathrm{pulsed} \mathrm{light} \mathrm{on} \mathrm{decontami-}$ nation, quality, and bacterial attachment of fresh raspberries. Food Microbiology, 2016; 57: 135-143. https://doi.org/10.1016/j.fm.2016.02.009

41. Gurtler, J. B. Pathogen decontamination of food crop soil: a review. J. food protection, 2017; 80(9): 14611470. https://doi.org/10.4315/0362-028X.JFP-17-040

42. Pignata C, D'angelo D, Fea E, Gilli G. A review on microbiological decontamination of fresh produce with nonthermal plasma. J. Applied Microbiology, 2017; 122(6): 1438-1455. https://doi.org/10.1111/ jam.13412

43. Tastan O, Pataro G, Donsi F, Ferrari G, Baysal T. Decontamination of fresh-cut cucumber slices by a combination of a modified chitosan coating containing carvacrol nanoemulsions and pulsed light. Int. J. Food Microbiol, 2017; 260: 75-80. https://doi. org/10.1016/j.ijfoodmicro.2017.08.011 